\title{
Sign language research in web of science
}

\author{
Engin Arik ${ }^{1,2 *}$ \\ ${ }^{1}$ Department Psychology, Acibadem, Dogus University FEF Kadikoy, Istanbul 34722, Turkey, ${ }^{2}$ Purdue University IDIS Linguistics Program 1239 \\ Beering Hall West Lafayette, IN, 47906, US
}

\begin{abstract}
This study investigates bibliometric characteristics of publications on sign languages indexed in the Science Citation Index Expanded and Social Science Citation Index between 1900 and 2013, and arts and humanities citation index between 1975 and 2013 in web of science (WoS). There were 2460 scientific publications on sign languages from a variety of research areas written in 14 languages with authors from 66 countries. $95.24 \%$ of them were written in English while $49.71 \%$ of authors were from the USA. Although the first publication appeared in 1902, the number of publications has recently increased: $86.26 \%$ of them were covered in WoS between 1990 and 2013. A majority of the publications were on American Sign Language and British Sign Language, with $63.46 \%$ and $9.33 \%$ of all publications, respectively. The number of sign language publications will continue to increase in WoS, covering a wider variety of sign languages.
\end{abstract}

Keywords: Bibliometric analysis, sign language, web of science

\section{INTRODUCTION}

Citation indices like web of science (WoS) cover timely published journals, which have referee systems and higher impact factors. ${ }^{[1]}$ These indices are crucial for storing, accessing, and disseminating information in previous and current scientific research and perhaps, establishing new research areas. Publications indexed in WoS gained increased attention from researchers and institutions to assess scientific productivity and quality of publication, and to compete with universities and research institutes (inter) nationally. Having publications in these indices appears to be important for job hunting of new $\mathrm{PhD}$ holders, promotion of faculty members, and the respectability of researchers in and across several fields of study. ${ }^{[2-6]}$

*Address for correspondence:

E-mail: enginarik@enginarik.com

\begin{tabular}{|c|c|}
\hline \multicolumn{2}{|c|}{ Access this article online } \\
\hline Quick Response Code: & \\
\hline \multirow{2}{*}{ 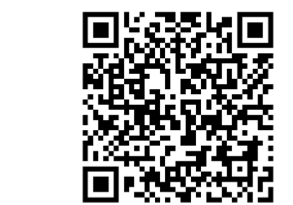 } & $\begin{array}{l}\text { Website: } \\
\text { www.jscires.org }\end{array}$ \\
\hline & $\begin{array}{l}\text { DOI: } \\
10.4103 / 2320-0057.153583\end{array}$ \\
\hline
\end{tabular}

The present study is the first attempt to investigate a relatively new field of study: Sign language research as covered in WoS. Sign language studies are of high importance for the following reason: Natural human languages have two types, spoken languages and sign languages. Even though studies investigating the sign languages of deaf people are relatively new compared to those investigating spoken languages, they are very crucial to exploring human language capacity from language emergence on Al-Sayyid Bedouin Sign Language and on Nicaraguan Sign Language to language acquisition. ${ }^{[7-11]}$ Studies are being conducted on sign languages from all aspects of linguistics, from grammar (American Sign Language; British Sign Language; and Australian Sign Language) to identity, education, culture, and language policies. ${ }^{[12-15]}$ There are already handbook-like publications on sign language studies. ${ }^{[16-18]}$ Tervoor $\mathrm{t}^{[19]}$ and Stokoe ${ }^{[20]}$ are often cited as the very first sign language linguistic studies. About 40 sign languages have already been discovered, and there are probably many more sign languages waiting for the attention of the scientific community. It is speculated that sign languages are as old as spoken languages. Moreover, it is well-documented that signed communication systems were in use in monasteries, courts, and palaces centuries ago, ${ }^{[21]}$ and that some sign languages emerged very recently. ${ }^{[21]}$ For example, the 
emergence of Nicaraguan Sign Language in the 1970s is well-documented. ${ }^{[8]}$

Sign languages have gained importance at the institutional level, too. There are currently two journals, Sign Language Studies (published since 2000) and Sign Language and Linguistics (published since 1998), devoted entirely to research on sign languages. Recently, the Sign Language Linguistics Society, an international organization of sign language linguists, was established. Since 1986, a major conference, Theoretical Issues in Sign Language Research, has taken place every 3-4 years. Moreover, Gallaudet University in the USA primarily serves the deaf community.

That being said, little is known about the extent to which sign language publications are represented in well-known indices. The current study fills this gap, focusing on the publications covered in WoS. The most important WoS indices are science citation index expanded (SCI-expanded), social science citation index (SSCI), and arts and humanities citation index (A and HCI). While the first two cover publications since 1900, A and HCI covers publications since 1975. Therefore, the current study examines the main bibliometric characteristics of scientific outputs of sign language research as represented in SCI-expanded, SSCI, and $\mathrm{A}$ and $\mathrm{HCI}$. It was hypothesized that as a relatively new research field, (1) the number of sign language publications has significantly increased in last decades, but (2) all known sign languages are not equally represented in WoS. The present study answers the following questions: What are the main bibliometric characteristics of sign language publications in SCI-Expanded and SSCI since 1900 and A and HCI since 1975? How often do publications on sign languages appear in WoS? Which sign languages are represented in WoS?

\section{METHODS}

To test the hypotheses and answer these research questions, WoS was accessed at http://apps.webofknowledge.com/ several times between January 2, 2014 and January 3, 2014 via Purdue University Libraries. Three major databases, SCI-expanded, SSCI, and A and HCI, were selected because sign language publications are covered in all of them.

The data were collected in the following way: First, after selecting SCI-Expanded, SSCI, and A and HCI, publication years were set as 1900-2013 and "sign language" was written as a keyword in the Topic search area. In this way, any publications that included "sign language" in their titles, keywords, or abstracts (if available in the database) were successfully accessed. Second, after careful examination, the same search was repeated by selecting years between 1900-1959, 1960-1969, 1970-1979, 1980-1989, 1990-1999, 2000-2009, and 2010-2013 to examine the changes in the number of publications over the years. Third, in order to access publications on sign languages listed $(n=40)$ in the literature, a similar search was conducted. To do so, in topic search, the official name of the sign language, such as "American Sign Language," "British Sign Language," “Turkish Sign Language" $(n=40)$, was typed. The results were then noted.

In all of these searches, all available data such as the number of publications, categories, document types, research areas, authors, group authors, editors, source titles, book series, conference titles, publication years, organizations, funding agencies, languages, and countries and territories were recorded. However, the present study focused mainly on publication years, number of publications, source titles, languages, and countries/territories. Note that since the data were collected in January 2014, some of the scientific publications from 2013 may not be available in SCI-expanded, SSCI or A and HCI yet. Therefore, the number of publications from 2013 may increase during the year of 2014 .

\section{RESULTS}

\section{Main Bibliometric Characteristics of Sign Language Publications}

There were a total of 2,460 publications. 1,890 of them $(76.82 \%)$ were articles, $238(9.67 \%)$ were book reviews, $212(8.6 \%)$ were proceedings, and the rest were reviews, meeting abstracts, notes, and so on. These publications were categorized and put into research areas in a variety of fields including rehabilitation, linguistics, psychology, and education [Tables 1 and 2].

Results showed that scientific outputs of sign language publications appeared in a variety of journals. Of them, American Annals of the Deaf (no. 1) and Journal of Deaf Studies and Deaf Education (no. 2) are devoted to studies on deaf studies and deaf education. Lecture Notes in Computer Science (no. 3) and Lecture Notes in Artificial Intelligence (no. 6) mainly cover studies from computer science. Brain and Language (no. 4) and Journal of Cognitive Neuroscience (no. 9) target (interdisciplinary) studies from neurosciences. Lingua (no. 5) and Language (no. 7) are 
journals of language studies. Cognition (no. 8) is a psychology journal focusing on human cognition, such as memory and language. Journal of Communication Disorders (no. 10) covers studies from all kinds of communication disorders, from deafness to stuttering [Table 3].

Web of science listed 66 countries/territories from which the authors contributed to these publications on sign languages. 31 of these countries had fewer than 5 publications. Almost half of these publications had an address in the

Table 1: Top 10 out of 100 categories covering sign language research between 1900 and 2013

\begin{tabular}{lcc}
\hline Category & $\mathbf{1 9 0 0 - 2 0 1 3}$ & Percentage \\
\hline Rehabilitation & 504 & 20.48 \\
Linguistics & 474 & 19.26 \\
Psychology Experimental & 355 & 14.43 \\
Education Special & 335 & 13.61 \\
Language Linguistics & 263 & 10.69 \\
Neurosciences & 263 & 10.69 \\
Computer Science Artificial Intelligence & 178 & 7.23 \\
Audiology Speech Language Pathology & 123 & 5.00 \\
Psychology & 103 & 4.18 \\
Engineering Electrical Electronic & 101 & 4.10 \\
\hline
\end{tabular}

Table 2: Top 10 out of 100 research areas covering sign language research between 1900 and 2013

\begin{tabular}{lcc}
\hline Research area & $\mathbf{1 9 0 0 - 2 0 1 3}$ & Percentage \\
\hline Psychology & 630 & 25.60 \\
Linguistics & 515 & 20.93 \\
Rehabilitation & 504 & 20.48 \\
Education Educational Research & 418 & 16.99 \\
Neurosciences Neurology & 319 & 12.96 \\
Computer Science & 294 & 11.95 \\
Engineering & 133 & 5.40 \\
Audiology Speech-Language Pathology & 123 & 5.00 \\
Psychiatry & 76 & 3.08 \\
Otorhinolaryngology & 61 & 2.47 \\
\hline
\end{tabular}

Table 3: Top 10 out of 100 journals publishing sign language studies between 1900 and 2013

\begin{tabular}{lcc}
\hline Journals & $\mathbf{1 9 0 0 - 2 0 1 3}$ & Percentage \\
\hline American Annals of the Deaf & 148 & 6.01 \\
Journal of Deaf Studies and Deaf Education & 102 & 4.14 \\
Lecture Notes in Computer Science & 58 & 2.35 \\
Brain and Language & 38 & 1.54 \\
Lingua & 34 & 1.38 \\
Lecture notes in Artificial intelligence & 30 & 1.21 \\
Language & 28 & 1.13 \\
Cognition & 26 & 1.05 \\
Journal of Cognitive Neuroscience & 26 & 1.05 \\
Journal of Communication Disorders & 25 & 1.01 \\
\hline
\end{tabular}

USA (1223), which was followed by England (236, 9.59\%), Canada (115, 4.67\%), France $(79,3.21 \%)$, and the Netherlands $(73,2.96 \%)$ [Table 4].

The organizations with which the authors were affiliated were universities in California, London, Gallaudet, and Rochester as appeared exactly in WoS [Table 5]. Of these institutions, Gallaudet University (no. 9) is the only university in the world established specifically for the higher education of the deaf. Among the top 10, two universities (University of London and University College London) are in England and the rest are in the USA.

Web of science indices covered publications on sign languages written in 14 different languages [Table 6]. But most of the publications were written in English (95.24\%), followed by French (1.86\%) and German (1.46\%).

\section{Publications in Historical Context}

The first publication on sign languages appeared in 1901, entitled "The sign language in American Schools" by Hanson,

Table 4: Top 10 out of 66 Countries/Territories publishing sign language research between 1900 and 2013

\begin{tabular}{lcc}
\hline Country & $\mathbf{1 9 0 0 - 2 0 1 3}$ & Percentage \\
\hline USA & 1223 & 49.71 \\
England & 236 & 9.59 \\
Canada & 115 & 4.67 \\
France & 79 & 3.21 \\
Netherlands & 73 & 2.96 \\
Japan & 72 & 2.88 \\
Germany & 71 & 2.88 \\
Australia & 60 & 2.43 \\
Spain & 57 & 2.31 \\
Israel & 51 & 2.07 \\
\hline
\end{tabular}

Table 5: Top 10 out of 100 organizations that authors publishing sign language research were affiliated with between 1900 and 2013

University (as in WoS)

$1900-2013$

University of California system

173

University of California San Diego

99

University of London

89

Salk Institute

Rochester Institute of Technology

California State University System

University College London

San Diego State University

Gallaudet University

University of Rochester 53 
and was published in Association Review by Alexander Graham Bell Association for the Deaf. ${ }^{[2]}$ This publication was cataloged in 1902 in WoS. Over the years in the selected time periods, the number of publications has increased multiple times, with publication languages increasing from 2 to 9 , and countries where the authors reside increasing from 1 to 58 [Table 7]. Nevertheless, these variations do not change the observation that most of the publications were in English and that almost half of the authors had an address in the USA.

By 1959, there were 21 publications on sign languages. Of them, only two publications (from Mathematics and Physics) were unrelated to sign language research. 17 of them were in English, and the rest were in German. Between 1960 and 1969, there were 13 publications on sign languages: 9 of them in English, 3 in German, and 1 in French. Of these publications, one of them, entitled "teaching sign language to a chimpanzee" was published in science. ${ }^{[23]}$

The number of publications increased by a factor of 7.5 in 1970-1979. 97 publications were on sign languages in this

\begin{tabular}{lcc}
$\begin{array}{l}\text { Table 6: Publication languages for output in sign } \\
\text { languages between } \\
\mathbf{1 9 0 0} \text { and } \mathbf{2 0 1 3}\end{array}$ \\
\hline Language & $\mathbf{1 9 0 0 - 2 0 1 3}$ & Percentage \\
\hline English & 2,343 & 95.24 \\
French & 46 & 1.86 \\
German & 36 & 1.46 \\
Spanish & 14 & 0.56 \\
Portuguese & 5 & 0.20 \\
Japanese & 4 & 0.16 \\
Dutch & 2 & 0.08 \\
Italian & 2 & 0.08 \\
Russian & 2 & 0.08 \\
Turkish & 2 & 0.08 \\
Croatian & 1 & 0.04 \\
Norwegian & 1 & 0.04 \\
Serbian & 1 & 0.04 \\
Swedish & 1 & 0.04 \\
\hline
\end{tabular}

Table 7: Sign language publications by time period between 1900 and 2013

\begin{tabular}{lcll}
\hline Time period & Publications & Languages (\%) & Countries (\%) \\
\hline $1900-1959$ & 21 & 2 (English 80.95) & 1 (USA) \\
$1960-1969$ & 13 & 3 (English 69.23) & 1 (USA) \\
$1970-1979$ & 97 & 4 (English 92.78) & 6 (USA 83.75) \\
$1980-1989$ & 207 & 3 (English 95.65) & 13 (USA 79.31) \\
$1990-1999$ & 511 & 6 (English 95.30) & 28 (USA 59.67) \\
$2000-2009$ & 1,001 & 9 (English 95.90) & 50 (USA 44.30) \\
$2010-2013$ & 610 & 9 (English 95.90) & 58 (USA 44.30) \\
\hline
\end{tabular}

period. 90 of them were written in English, 4 in French, 2 German, and 1 in Norwegian. Before this period, WoS gave country information for a few publications, all in the USA. In this period, several countries were listed: USA (67), Canada (9), Belgium (1), Denmark (1), England (1), and the [former] Federal Republic of Germany (1). Between 1980 and 1989, a total of 207 outputs were sign language publications. These publications came from 13 countries: USA (138), Canada (9), England (7), Australia (4), Germany (3), Japan (3), Denmark (2), France (2), New Zealand (2), Belgium (1), Ireland (1), Netherlands (1), and North Ireland (1) written in English (198), French (5), and German (4).

Not only has the number of publications increased, but the languages they were written in as well as the author's home countries have become more varied. Between 1990 and 1999, there were 511 publications on sign languages written in English (487), German (10), French (8), Italian (2), Japanese (2), and Spanish (2). These were the output of 28 different countries. Between 2000 and 2009, a total of 1001 outputs were published on sign languages, written in 9 different languages: English (960), French (22), German (7), Spanish (5), Dutch (2), Japanese (2), Portuguese (1), Russian (1), and Swedish (1). These publications came from 50 different countries. In the last 4 years from 2010 to 2013, there have already been 610 publications on sign languages written in nine different languages: English (582), Spanish (7), French (6), German (6), Portuguese (4), Turkish (2), Croatian (1), Russian (1), and Serbian (1). These publications came from 58 countries.

\section{Comparisons of Publications on Sign Languages}

In the literature, there were observations reported on about 40 different sign languages. ${ }^{[17,18]}$ The output of scientific publications on these sign languages is compared in the following [Table 8]. Results showed that there were no publications on 8 out of 40 sign languages indexed in SCI-Expanded, SSCI, and A and HCI. These sign languages were Adamorobe Sign Language, Icelandic Sign Language, Kenyan Sign Language, Lebanese Sign Language, Quebec Sign Language, South Korean Sign Language, Tanzania Sign Language, and Ugandan Sign Language. Of the other 32 sign languages, the sign language studied most often was American Sign Language (721).

\section{DISCUSSION AND CONCLUSION}

This study investigated the outputs of scientific publications on sign languages indexed in three WoS 
Arik: Sign language research in web of science

Table 8: Sign languages as represented in SCI-Expanded, SSCI, and A and HCI (listed alphabetically)

\begin{tabular}{|c|c|c|c|}
\hline Sign language & Publications & Publication languages & Countries \\
\hline Al-Sayyid Bedouin Sign Language & 8 & English & 2 \\
\hline Argentinian Sign Language & 1 & English & 2 \\
\hline American Sign Language & 721 & English, German, Japanese, Spanish & 33 \\
\hline Australian Sign Language & 19 & English & 9 \\
\hline Brazilian Sign Language & 13 & English, Portuguese & 3 \\
\hline British Sign Language & 106 & English & 14 \\
\hline Catalan Sign Language & 2 & English & 2 \\
\hline Chinese Sign Language & 21 & English & 5 \\
\hline German Sign Language & 22 & English, German & 7 \\
\hline Finnish Sign Language & 5 & English & 2 \\
\hline Flemish Sign Language & 5 & English & 4 \\
\hline French Sign Language & 25 & English, French & 5 \\
\hline Greek Sign Language & 11 & English & 3 \\
\hline Hong Kong Sign Language & 3 & English & 2 \\
\hline Indo-Pakistani Sign Language & 1 & English & 1 \\
\hline Irish Sign Language & 1 & English & 2 \\
\hline Israeli Sign Language & 12 & English & 4 \\
\hline Italian Sign Language & 16 & English & 7 \\
\hline Japanese Sign Language & 27 & English, Japanese & 6 \\
\hline Kata Kolok & 2 & English & 2 \\
\hline Nicaraguan Sign Language & 27 & English & 10 \\
\hline Norwegian Sign Language & 4 & English & 3 \\
\hline New Zealand Sign Language & 6 & English & 3 \\
\hline Portuguese Sign Language & 2 & English & 1 \\
\hline Russian Sign Language & 2 & English & 1 \\
\hline Sign Language of the Netherlands & 21 & English & 3 \\
\hline Spanish Sign Language & 25 & English, Spanish & 4 \\
\hline Swedish Sign Language & 6 & English & 1 \\
\hline Taiwanese Sign Language & 10 & English & 1 \\
\hline Thai Sign Language & 4 & English & 3 \\
\hline Turkish Sign Language & 7 & English, Turkish & 1 \\
\hline Urubu Sign Language & 1 & English & 1 \\
\hline
\end{tabular}

$\mathrm{SCI}=$ Science citation index, $\mathrm{SSCI}=$ Social science citation index, $\mathrm{A}$ and $\mathrm{HCI}=$ Arts and humanities citation index

indices: SCI-Expanded and SSCI between 1900 and 2013, and A and HCI between 1975 and 2013. Results provided supporting evidence for hypothesis 1: The number of sign language publications has increased in recent decades. One could argue that this might be the effect of the gradual increase in WoS coverage. For example, research showed that the number of linguistics publications covered in SSCI and $\mathrm{A}$ and $\mathrm{HCI}^{[31]}$ and psychology publications covered in $\mathrm{SSCI}^{[32]}$ has increased over the years. However, research also showed that their increase is parallel to the increase in overall publications covered in WoS indices. This is not the case in the output of sign language publications. The first publication on sign language appeared as early as 1902 in WoS and the first 21 publications between 1900 and 1959 were covered in WoS. Yet, $86.26 \%$ of all publications on sign languages were published in the last 30 years, as indexed in WoS between 1990 and 2013, which cannot be the sole result of the increase in WoS coverage.

This finding suggests that there is a growing interest for a variety of scientific communities in investigating issues in sign languages. That is what was found in the present study. Results showed that publications on sign languages came from a diverse field of studies such as psychology, linguistics, rehabilitation, education, neurosciences, computer science, engineering, audiology, speech-language pathology, psychiatry, and otorhinolaryngology, suggesting that studies on sign language research are inter- and cross-disciplinary in nature. While some of these fields, such as rehabilitation, (special) education, audiology, speech-language pathology, and otorhinolaryngology, are interested in sign languages because one of their main foci 
is deafness and deafness related topics, some others go beyond this, such as psychology of language, developmental and cognitive psychology, language acquisition, grammar, brain and language, gesture and sign recognition, and language preservation and documentation, among others. Thus, it is expected that amount of publications on sign languages will continue to increase in the future.

The results also provided supporting evidence for hypothesis 2: All known sign languages are not equally represented in WoS. It was found that WoS covered publications on 32 different sign languages, but the majority of publications were on American Sign Language (63.46\%) and British Sign Language $(9.33 \%)$. There were 5 or fewer publications on 13 of 40 sign languages, and no publications on 8 sign languages. Since many sign languages are waiting for further exploration, it is expected that there will be an increase in the publications on sign languages in the future.

Furthermore, 95.24\% of the sign language publications were written in English. This is not surprising because it has already been observed that today more than $98 \%$ of scientific publications are in English. ${ }^{[24]}$ This inevitably creates a language barrier for publications written in languages other than English, which can be outside of the WoS coverage. ${ }^{[25]}$ In addition, the authors of all publications on sign languages came from 66 countries, and yet, $49.71 \%$ of them were from the USA, which was also observed in the outputs of scientific publications in linguistics covered in SSCI and AandHCI ${ }^{[31]}$ and psychology covered in SSCI. ${ }^{[32]}$

There are limitations in bibliometric analyses of social sciences and humanities based solely on WoS. ${ }^{[2]}$ Therefore, future research will investigate publications on sign languages covered by field-specific databases such as Linguistics and Language Behavior Abstracts and PsycINFO of American Psychological Association. Future research will also investigate monographs and edited books on sign languages, citation patterns in articles as well as books and book chapters, ${ }^{[27-30]}$ and authorship patterns including acknowledgments. ${ }^{[33]}$

\section{REFERENCES}

1. Russ-Eft D. SSCI, ISI, JCR, JIF, IF, and journal quality. Hum Resour Dev Q 2008;19:185-9.

2. Lawrence PA. Rank injustice. Nature $2002 ; 415: 835-6$.

3. Lawrence PA. The politics of publication. Nature 2003;422:259-61.

4. Lawrence PA. Lost in publication: How measurement harms science? Ethics Sci Environ Polit 2008;8:9-11.

5. Reich ES. Science publishing: The golden club. Nature 2013;502:291-3.
6. Owens B. Research assessments: Judgement day. Nature 2013;502:288-90.

7. Sandler W, Meir I, Padden C, Aronoff M. The emergence of grammar: Systematic structure in a new language. Proc Natl Acad Sci U S A 2005;102:2661-5.

8. Senghas A, Kita S, OzyürekA. Children creating core properties of language: Evidence from an emerging sign language in Nicaragua. Science 2004;305:1779-82.

9. Mayberry RI, Eichen EB. The long-lasting advantage of learning sign language in childhood: Another look at the critical period for language acquisition. J Mem Lang 1991;30:486-512.

10. Lillo-Martin D. Sign language acquisition studies. In: Bavin EL, editor. The Cambridge Handbook of Child Language. New York, NY: Cambridge University Press; 2009. p. 399-415.

11. Chamberlain $\mathrm{C}$, Morford J, Mayberry R, editors. Language Acquisition by Eye. Mahwah, NJ: Lawrence Erlbaum Associates; 2000.

12. Neidle C, Kegl J, MacLaughlin D, Bahan B, Gee RG. The Syntax of American Sign Language: Functional Categories and Hierarchical Structure. Cambridge, MA: The MIT Press; 1999.

13. Sutton-Spence R, Woll B. Linguistics of British Sign Language. Cambridge, MA: Cambridge University Press; 1999.

14. Johnston T, Schembri A. Australian Sign Language (AUSLAN): An Introduction to Sign Language Linguistics. Cambridge, MA: Cambridge University Press; 2007.

15. Lucas $C$, editor. The Sociolinguistics of Sign Languages. Cambridge, MA: Cambridge University Press; 2001.

16. Sandler W, Lillo-Martin D. Sign Language and Linguistic Universals. New York, NY: Cambridge University Press; 2006.

17. Brentari D, editor. Sign Languages. Cambridge, MA: Cambridge University Press; 2010.

18. Pfau R, Steinbach M, Woll B. Sign Language: An International Handbook. Berlin, Germany: Mouton de Gruyter; 2012.

19. Tervoort BT. Structurele Analyse van Visueel Taalgebruik Binnen Een Groep Dove Kinderen. Amsterdam, NL: Noord-Hollandsche Uitgevers Maatschappij; 1953.

20. Stokoe W. Sign Language Structure. An Outline of the Visual Communication System of the American Deaf. Silver Spring, MD: Linstok Press; 1960.

21. Miles M. Signing in the seraglio: Mutes, dwarfs and gestures at the Ottoman court 1500-1700. Disabil Soc 2000;15:115-34.

22. Hanson $\mathrm{O}$. The sign language in American schools. Assoc Rev 1901;3:27-30.

23. Gardner RA, Gardner BT. Teaching sign language to a chimpanzee. Science 1969;165:664-72.

24. Engber D. FYI: How Did English Get to Be The International Language of Science? Popular Science. Available from: http:// www.popsci.com/article/science/fyi-how-did-english-get-beinternational-language-science. [Last retrieved on 2015 Feb 1].

25. van Leeuwen T. Bibliometric research evaluations, Web of science and the social sciences and humanities: A problematic relationship? Bibliometrie Prax Forsch 2013;2:1-18.

26. Archambault $E$, Larivière $W$. The limits of bibliometrics for the analysis of the social sciences and humanities literature. World Soc Sci Rep; 2010.

27. Larivière $V$, Archambault É, Gingras Y, Vignola-Gagné É. The place of serials in referencing practices: Comparing natural sciences and engineering with social sciences and humanities. J Am Soc Inf Sci Technol 2006;57:997-1004.

28. Nederhof AJ. Bibliometric monitoring of research performance in the Social sciences and the humanities: A review. Scientometrics 2006;66:81-100.

29. Nederhof AJ, van Leeuwen TN, van Raan AF. Highly cited non-journal publications in political science, economics and psychology: A first exploration. Scientometrics 2010;83:363-74.

30. Linmans AJ. Why with bibliometrics the Humanities does not need to be the weakest link Indicators for research evaluation 
based on citations, library holdings, and productivity measures. Scientometrics 2010;83:337-54.

31. Arik E. A bibliometric analysis of linguistics in web of science. Journal of Scientometric Research. Forthcoming.

32. Arik E. Web of Knowledge'da Türkiye Adresli Psikoloji Yayınlarına Genel Bir Bakış: 1980-2013 [Turkey's Output in Psychological Publications: An Overview of Web of Knowledge between 1980 and 2013]. Eleştirel Psikoloji Bülteni 2014;5;81-96.
33. Sula CA. Visualizing social connections in the humanities: Beyond bibliometrics. Bull Am Soc Inf Sci Technol 2012;38:31-5.

How to cite this article: Arik E. Sign language research in web of science. J Sci Res 2014;3:143-9.

Source of Support: Nil, Conflict of Interest: None declared

\section{Staying in touch with the journal}

1) Table of Contents (TOC) email alert Receive an email alert containing the TOC when a new complete issue of the journal is made available online. To register for TOC alerts go to www.jscires.org/signup.asp.

\section{2) RSS feeds}

Really Simple Syndication (RSS) helps you to get alerts on new publication right on your desktop without going to the journal's website. You need a software (e.g. RSSReader, Feed Demon, FeedReader, My Yahoo!, NewsGator and NewzCrawler) to get advantage of this tool. RSS feeds can also be read through FireFox or Microsoft Outlook 2007. Once any of these small (and mostly free) software is installed, add www.jscires.org/rssfeed.asp as one of the feeds. 